\title{
PEMIKIRAN FILOSOFIS DAN TEORI KONTEMPORER TENTANG PENDIDIKAN
}

Fatkhul Mubin

fatkhulmubin90@gmail.com

PENDAHULUAN

\section{A. LATAR BELAKANG}

Filsafat telah ada sejak manusia itu ada (Pidarta,2001). Filsafat berasal dari bahasa Yunani, taitu philos yang artinya cinta dan Sophia yang artinya kebijaksanaan atau kebenaran. Jadi, filsafat artinya cinta akan kebijaksanaan atau kebenaran. Filsafat berarti pula pendirian hidup atau pandangan hidup. Secara ilmiah definisi filsafat yaitu usaha berpikir radikal dan hasil yang diperoleh dari menggambarkan dan menyatakan suatu pandangan yang menyeluruh secara sistematis tentang alam semesta serta tempat dilahirkannya manusia. Filsafat mencakup keseluruhan pengetahuan manusia, filsafat merupakan sumber ide paling dalam bagi segala macam ilmu pengetahuan, sehingga filsafat disebut juga induk pengetahuan.

Pendidikan adalah upaya mengembangkan potensi-potensi manusiawi peserta didik baik potensi fisik potensi cipta, rasa, maupun karsanya, agar potensi itu menjadi nyata dan dapat berfungsi dalam perjalanan hidupnya. Dasar pendidikan adalah cita-cita kemanusiaan universal. Pendidikan bertujuan menyiapkan pribadi dalam keseimbangan, kesatuan. organis, harmonis, dinamis. guna mencapai tujuan hidup kemanusiaan. ${ }^{1}$

\footnotetext{
1 Saihu, S. (2019). RINTISAN PERADABAN PROFETIK UMAT MANUSIA MELALUI PERISTIWA TURUNNYA ADAM AS KE-DUNIA. Mumtaz: Jurnal Studi Al-Quran dan Keislaman, 3(2), 268-279,

Saihu, S. (2019). Pendidikan Pluralisme Agama: Kajian tentang Integrasi Budaya dan Agama dalam Menyelesaikan Konflik Sosial Kontemporer. Jurnal Indo-Islamika, 9(1), 67-90,

Saihu, S. (2019). IMPLEMENTASI MANAJEMEN BALANCED SCORECARD DI PONDOK PESANTREN JAM'IYYAH ISLAMIYYAH TANGERANG SELATAN. Mumtaz: Jurnal Studi Al-Quran dan Keislaman, 3(1), 1-22.

Saihu, S. (2019). KOMUNIKASI PENDIDIK TERHADAP ANAK BERKEBUTUHAN KHUSUS DI SEKOLAH KHUSUS ASY-SYIFA LARANGAN. Andragogi: Jurnal Pendidikan Islam dan Manajemen Pendidikan Islam, 1(3), 418-440.

Saihu, S., \& Marsiti, M. (2019). PENDIDIKAN KARAKTER DALAM UPAYA MENANGKAL RADIKALISME DI SMA NEGERI 3 KOTA DEPOK, JAWA BARAT. Andragogi: Jurnal Pendidikan Islam dan Manajemen Pendidikan Islam, 1(1), 23-54.
} 
Filsafat pendidikan ialah hasil pemikiran dan perenungan secara mendalam samapai akar-akarnya mengenai pendidikan (Pidarta,2001). Landasan filosofi pendidikan adalah seperangkat filosofi yang dijadikan titik tolak dalam pendidikan. Landasan filosofis pendidikan sesungguhnya merupakan suatu sistem gagasan tentang pendidikan dan dedukasi atau dijabarkan dari suatu sistem gagasan filsafat umum yang diajurkan oleh suatu aliran filsafat tertentu. Terdapat hubungan implikasi antara gagasan-gagasan dalam cabang-cabang filsafat umum tehadap gagasan-agasan pendidikan. Landasan filosofis pendidikan tidak berisi konsep-konsep tentang pendidikan apa adanya, melainkan berisi tentang konsep-konsep pendidikan yang seharusnya atau yang dicita-citakan.

Landasan filosofis pendidikan merupakan bagian penting yang harus dipelajari dalam dunia pendidikan, hal ini dikarenakan pendidikan bersifat normatif dan perspektif. Selain itu juga, dengan filosofis pendidikan kita akan mengetahui mengapa, apa, dan bagaimana kita melakukan pelajaran, siapa yang kita ajar dan mengenai hakikat belajar. Hal ini merupakan seperangkat prinsip yang menuntun kita dalam melakukan tindakan profesional melalui kegiatan dan masalah-masalah yang kita hadapi sehari-hari. .Berdasarkan uraian di atas, penulis merumuskan masalah mengenai pemikiran filosifis dan teori kontenporer tentang pendidikan

\section{B. RUMUSAN MASALAH}

1. Bagaimana pemikiran filosifis dan teori kontenporer tentang pendidikan pedagogy of the oppressed dari Paulo Freire, critical pedagogy dari mazhab Frankfurt, pendidikan plural-multikultural dari James A. Bank dan Muhammad Legenhousen, konsep pendidikan integratif paideia dari HansGeorg Gadamer, konsep pendidikan terpadu: kontribusi neurophilosophy dan non-dualistika fisika kuantum, konsep pendidikan sebagai teaching to think dari Franz Kafka, dan konsep pendidikan kosmopolitan dari Bernard J. F. Lonergan.

\section{TUJUAN PEMBAHASAN}

1. Untuk mengetahui bagaimana pemikiran filosifis dan teori kontenporer tentang pendidikan. 


\section{PEMBAHASAN}

\section{A. Pedagogy of the oppressed dari Paulo Freire}

Freire dilahirkan dalam keluarga kelas menengah di Recife, Brasil. Namun ia mengalami langsung kemiskinan dan kelaparan pada masa Depresi Besar 1929, suatu pengalaman yang membentuk keprihatinannya terhadap kaum miskin dan ikut membangun pandangan dunia pendidikannya yang khas.

Freire mulai belajar di Universitas Recife pada 1943, sebagai seorang mahasiswa hukum, tetapi ia juga belajar filsafat dan psikologi bahasa. Meskipun ia lulus sebagai ahli hukum, ia tidak pernah benar-benar berpraktik dalam bidang tersebut. Sebaliknya, ia bekerja sebagai seorang guru di sekolah-sekolah menengah, mengajar bahasa Portugis. Pada 1944 ia menikah dengan Elza Maia Costa de Oliveira, seorang rekan gurunya. Mereka berdua bekerja bersama selama hidupnya sementara istrinya juga membesarkan kelima anak mereka. ${ }^{2}$

Ia merupakan seorang pemikir yang dikenal dengan gagasan gagasanya terutama masalah pendidikan kaum tertindas. Pemikiranya ini memberikan sumbangsih yang besar bagi perbaikan sistem pendidikan pada masanya pun sampai sekarang. Gagasan Freire sebenarnya bukanlah gagasan yang benar benar baru, dia mengakui bahwa gagasanya adalah akumulasi dari pemikir pemikir pendhulunya seperti ; Sartre, Martin Luther King Jr, Che Guevara, Mao Tse Tung, dsb.

\footnotetext{
2 https://id.wikipedia.org/wiki/Paulo Freire, Saihu, S. (2019). KONSEP MANUSIA DAN IMPLEMENTASINYA DALAM PERUMUSAN TUJUAN PENDIDIKAN ISLAM MENURUT MURTADHA MUTHAHHARI. Andragogi: Jurnal Pendidikan Islam dan Manajemen Pendidikan Islam, 1(2), 197-217. Saihu, S., \& Rohman, B. (2019). PEMBENTUKAN KARAKTER MELALUI MODEL PENDIDIKAN TRANSFROMATIFE LEARNING PADA SANTRI DI PONDOK PESANTREN NURUL IKHLAS BALI. Edukasi Islami: Jurnal Pendidikan Islam, 8(02), 435-452.

Saihu, S., \& Taufik, T. (2019). PERLINDUNGAN HUKUM BAGI GURU. Al Amin: Jurnal Kajian Ilmu dan Budaya Islam, 2(2), 105-116.

Saihu, S. (2020). KONSEP PEMBAHARUAN PENDIDIKAN ISLAM MENURUT FAZLURRAHMAN. Andragogi: Jurnal Pendidikan Islam dan Manajemen Pendidikan Islam, 2(1), 82-95.

Saihu, S. (2020). ETIKA MENUNTUT ILMU MENURUT KITAB TA'LIM MUTA'ALIM. Al Amin: Jurnal Kajian Ilmu dan Budaya Islam, 3(1), 99-112.

Saihu, Aziz, A., Mubin, F., \& Sarnoto, A. Z. (2020). Design of islamic education based on local wisdom (An analysis of social learning theories in forming character through ngejot tradition in bali). International Journal of Advanced Science and Technology, 29(6), 1278-1293.
} 
Bagi dia Manusia adalah penguasa atas dirinya, dan karena itu fitrah manusia adalah menjadi merdeka, menjadi bebas. Ini merupakan tujuan akhir dari upaya humanisasinya Freire. Kebebasan dari situasi situasi yang menindas. Begitupun dalam suatu proses pendidikan haruslah ada kebebasan dan penyadaran bagi peserta didik.

Namun, sistem pendidikan yang pernah ada dan masih sampai saat ini adalah pendidikan gaya "bank" dimana pelajar diberi ilmu agar kelak mendatangkan hasil yang berlipat ganda. Jadi anak didik adalah obyek investasi dan sumber deposito potensial. Mereka tidak berbeda dengan komoditi ekonomis lainya yang lazim dikenal. Depositor atau investor adalah guru yang mewakili lembaga kemasyarakatan yang berkuasa, sementara depositonya berupa ilmu pengetahuan yang diajarkan kepada anak didik. Anak didikpun lantas diperlakukan sebagai "bejana kosong” yang akan diisi, sebagai sarana tabungan, atau penananaman ilmu pengetahuan yang dipetik hasilnya kelak. Jadi guru adalah subyek aktif sedangkan sang anak adalah obyek pasif yang penurut, sebagai obyek ilmu pengetahuan yang berifat teoritis dan tidak berkesadaran. Pendidikan akhirnya bersifat negatif dimana para guru memberi informasi yang harus ditelan oleh murid, yang wajib diingat dan dihafalkan. ${ }^{3}$

Pada akhirnya guru menjadi pusat segalanya, seperti pepatah yg sering kita dengar Guru = Digugu dan Ditiru. Hal ini membuat murid akan menjadikan diri mereka sebagai duplikasi guru, dan jika mereka kelak pun menjadi guru sistem yg akan mereka ajarkan pun demikian. Sistem pendidikan karena itu, menjadi sarana terbaik untuk memelihara keberlangsungan status quo sepanjang masa bukan menjadi penggugah keperubahan pembaharuan. Pola pendidikan seperti itu paling jauh hanya akan merubah "penafsiran" seseorang terhadap situasi yang dihadapinya, namun tidak mampu merubah "realitas" dirinya sendiri. Manusia menjadi penonton dan peniru, bukan pencipta.Sistem pendidikan pembaharu kata Freire

\footnotetext{
${ }^{3}$ Freire P. Pedagogi Orang Tertindas /Pedagogy of the Oppressed. ( Continuum: London : 2000.), Ronaldo, R., Zulfikar, A., Saihu, Ismail, \& Wekke, I. S. (2020). International relations of the asia pacific in the age of trump. Journal of Environmental Treatment Techniques, 8(1), 244-246.

Saihu, M. M., \& Aziz, A. (2020). Implementasi Metode Pendidikan Pluralisme Dalam Mata Pelajaran Pendidikan Agama Islam. Belajea; Jurnal Pendidikan Islam, 5(1), 131-150.

Saihu, M. (2019). Urgensi 'Urf dalam Tradisi Male dan Relevansinya dalam Dakwah Islam di JembranaBali. Jurnal Bimas Islam, 12(1), 173-201.

Saihu, S. (2020). The Effect of Using Talking Stick Learning Model on Student Learning Outcomes in Islamic Primary School of Jamiatul Khair, Ciledug Tangerang. Tarbawi: Jurnal Keilmuan Manajemen Pendidikan, 6(01), 61-68.

Saihu, S. (2020). Pendidikan sosial yang terkandung dalam Surat At-Taubah Ayat 71-72. Edukasi Islami: Jurnal Pendidikan Islam, 9(01), 127-148.
} 
adalah pendidikan untuk pembebasan bukan untuk penguasaan. Pendidikan menjadi proses kemerdekaan bukan penjinakan. ${ }^{4}$

Bagi Freire pendidikan sebaiknya justru harus menjadi kekuatan penyadar dan pembebebasan. Sistem pendidikan mapan telah menjadikan anak didik sebagai manusia manusia yang terasing dan tercabut dari realitas dirinya sendiri dan realitas dunia sekitarnya. Padahal proses pendidikan merupakan daur bertindak dan berpikir yang berlangsung secara terus menerus. Dengan seperti ini sehingga setiap anak didik secara langsung dilibatkan dalam permasalahan permasalahan realitas dunia dan keberadaan diri mereka didalamnya. Anak didik menjadi subjek yang belajar, subjek yang bertindak dan berpikir, dan berbicara menyatakan hasil tindakan, begitupun sang guru. Jadi keduanya saling belajar satu sama lain, saling memanusiakan. Hubungan keduanya pun menjadi subyek subyek, bukan subyek objek, dan obyek mereka adalah realita. Memahami obyek secara bersama, bukan seperti "gaya bank" yang bersifat antidoalogis.

\section{B. Critical pedagogy dari mazhab Frankfurt}

Mazhab Frankfurt (bahasa Jerman: Frankfurter Schule) adalah sebuah istilah yang diberikan kepada pemikiran yang dihasilkan oleh kelompok filsuf yang memiliki afiliasi dengan Institut für Sozialforschung di Frankfurt, Jerman, dan pemikir-pemikir lainnya yang dipengaruhi oleh mereka. Tahun yang dianggap sebagai tahun kemulaian Mazhab Frankfurt ini adalah tahun 1930, ketika Max Horkheimer diangkat sebagai direktur lembaga riset sosial tersebut. Beberapa filsuf terkenal yang dianggap sebagai anggota Mazhab Frankfurt ini antara lain Theodor Adorno, Walter Benjamin, dan Jürgen Habermas. Perlu diingat bahwa para

\footnotetext{
${ }^{4}$ Freire, Paulo.1999.Politik Pendidikan : Kebudayaan, Kekuasaan, dan Pembebasan. Diterjemahkan oleh : Agung Prihantoro \& Fuad Arif Fudiyanto.Yogyakarta : ReaD \& Pustaka Pelajar, Aziz, A., \& Saihu, S. (2019). Interpretasi Humanistik Kebahasaan: Upaya Kontekstualisasi Kaidah Bahasa Arab. Arabiyatuna: Jurnal Bahasa Arab, 3(2), 299-214

Saihu, S. (2019). PENDIDIKAN KARAKTER BERBASIS KEARIFAN LOKAL (STUDI DI JEMBRANA BALI). Edukasi Islami: Jurnal Pendidikan Islam, 8(01), 69-90.

Şahin, C. RELIGIA.

Saihu, S., \& Mailana, A. (2019). Teori pendidikan behavioristik pembentukan karakter masyarakat muslim dalam tradisi Ngejot di Bali. Ta'dibuna: Jurnal Pendidikan Islam, 8(2), 163-176.

Mubin, F. KEADILAN DALAM GENDER: KAJIAN KEPEMIMPINAN WANITA DALAM ISLAM1,

Saihu, M. (2019). Merawat Pluralisme Merawat Indonesia (Potret Pendidikan Pluralisme Agama Di JembranaBali). Deepublish.

Mubin, F. (2019). TAFSIR EMANSIPATORIS: PEMBUMIAN METODOLOGI TAFSIR PEMBEBASAN. Mumtaz: Jurnal Studi Al-Quran dan Keislaman, 3(1), 131-151.

Mubin, F. MODEL-MODEL PEMBELAJARAN BERBASIS MADRASAH DAN KEGIATAN LAIN YANG DIPERLUKAN DI DALAMNYA (FAKTOR PENDUKUNGNYA).
} 
pemikir ini tidak pernah mendefinisikan diri mereka sendiri di dalam sebuah kelompok atau 'mazhab', dan bahwa penamaan ini diberikan secara retrospektif. Walaupun kebanyakan dari mereka memiliki sebuah ketertarikan intelektual dengan pemikiran neo-Marxisme dan kritik terhadap budaya (yang di kemudian hari memengaruhi munculnya bidang ilmu Studi Budaya), masing-masing pemikir mengaplikasikan kedua hal ini dengan cara-cara dan terhadap subyek kajian yang berbeda.

Pedagogi kritis (critical pedagogy) merupakan pendekatan pembelajaran yang berupaya membantu murid mempertanyakan dan menantang dominasi serta keyakinan dan praktekpraktek yang mendominasi. Pedagogi kritis (critical pedagogy) dapat dimaknai sebagai pendidikan kritis yaitu pendidikan yang selalu mempertanyakan mengkritisi pendidikan itu sendiri dalam hal-hal fundamental tentang pendidikan baik dalam tataran filosofis, teori, sistem, kebijakan maupun implementasi implementasi. ${ }^{5}$

Dalam tataran filosofis pedagogi kritis merupakan tantangan dan kritik akan kemapanan modernisme serta kebijakan dan penyelenggaraan pendidikan yang bersifat oppresive dalam situasi sosial yang juga opresif karena mengacu pada pandangan metanarasi/grand narasi yang mengabaikan narasi-narasi lokal. Oleh karena itu pedagogi kritis sering diindukan/diilhami/terkait dengan mazhab Frankfurt dan post modernisme, non essensialisme karena tekanan yang amat kuat pada pendidikan sebagai praktek pembebasan manusia dari tatanan sosial ekonomi yang termanifestasikan dalam proses pendidikan. Pedagogi kritis mendapat pengaruh yang kuat dari pemikiran-pemikiran Paulo Freire (sering dipandang sebagai pelopor pemikir pedagogi kritis) seorang pendidik asal Brazil (pernah menjadi Menteri Pendidikan) yang dalam karya tulisnya (bukunya antara lain : Education as the practice of liberation, Pedagogy oh the oppressed, pedagogy of the heart, The Politic of Education, Culture, Power, and Liberation) menjelaskan/mengelaborasi bagaimana pendidikan harus dilaksanakan dalam upaya membebaskan manusia situasi sosial dan pendidikan yang menekan, mendominasi dan menjadikan manusia harus menerima apa adanya dalam situasi sosial yang ada tanpa menyadari dan mengkritisi situasi tersebut.

Tokoh Mazhab Frankfurt lain yang ternama adalah Max Horheimer (1895-1973). Pada tahun 1930 ia menjadi direktur Institut für Sozialforschung tersebut. Tokoh yang juga kondang adalah Theodor Wesengrund Adorno (1903-1969). Tokoh lainnya yaitu Herbert

\footnotetext{
${ }^{5}$ https://akhmadsudrajat.wordpress.com/2010/07/22/pendidikan-kritis/
} 
Marcuse (1898-1979) adalah figur yang paling terkenal karena ide-idenya memberikan inspirasi dan arah kepada gerakan "Kiri Baru" pada tahun 1960-an. Tokoh-tokoh lain dari mazhab ini adalah Friedrich Pollock, Leo Löwenthal, Walter Benjamin, Franz Neumann, Otto Kirchheimer, dan Karl August Wittfogel. Crozier (2005) menyebut kelompok ini sebagai "generasi pertama". Sedangkan "generasi kedua" terdiri dari Jürgen Habermas, Albrecht Wellmer, Oskar Negt, Claus Offe, Alfred Schmidt dan Klaus Eder. ${ }^{6}$

Teori Kritis merupakan teori yang reflektif. Artinya, teori itu tidak langsung saja mengenai salah satu masalah, melainkan dalam menangani sebuah masalah, ia menyadari dirinya sendiri, ia merefleksikan perannya sendiri sebagai teori. Masalah yang dibahas oleh teori tidak terpisah dari teori itu sendiri. Oleh karena itu Teori Kritis membedakan antara teori kontemplatif dan teori kritis. Teori kritis menjadi praktis, artinya: mempunyai dampak pada perubahan realitas.

Maka Teori Kritis meyakini bahwa ilmu pengetahuan tidak pernah menghasilkan “pengetahuan objektif". Hasil sebuah penelitian sejak semula sudah diarahkan pada metode yang dipakai di dalamnya. Penetapan metode penelitian dengan sendirinya selalu berdasarkan suatu penilaian atau kepentingan. Menurut Habermas, sangatlah penting bagi kita untuk memperhatikan kaitan antara hasil penelitian dan kepentingan kita. Jadi tidak ada satu ilmu pengetahuan pun yang bebas nilai. Menurut Hardiman (2003), dalam merintis sebuah Teori Kritis, Mazhab Frankfurt bermaksud untuk meneruskan tradisi ilmiah yang sudah dicapai modernitas tanpa terjerumus dalam determinisme ala ilmu-ilmu alam. Artinya, mereka tetap bergerak dalam tradisi borjuasi yang menjunjung otonomi pribadi dan rasionalitas, namun sudah dimuati dengan kesadaran sosial. Mereka ingin mencapai sebuah cita-cita "otonomi kolektif", suatu bentuk kebebasan yang disertai rasa tanggung jawab moral universal.

C. Pendidikan plural-multikultural dari James A. Bank dan Muhammad Legenhousen

Pengertian multikulturalisme diberikan oleh para ahli sangat beragam, multikulturalisme pada dasarnya adalah pandangan dunia yang kemudian dapat diterjemahkan dalam berbagai

${ }^{6} \mathrm{https} / / /$ www.academia.edu/1845413/MEMBERDAYAKAN_YANG_TERTINDAS_DARI_FRANKFU RT_KE_YOGYAKARTA 
kebijakan kebudayaan yang menekankan tentang penerimaan terhadap realitas keagamaan yang pluralis dan multikultural yang ada dalam kehidupan masyarakat. ${ }^{7}$

Pembumian wacana multikulturalisme pada ranah pendidikan formal (sekolah) dewasa ini semakin menggeliat. Maraknya gagasan multikulturalisme disertai dengan penyebaran isu pendahuluan: banyaknya peristiwa bentrokan dan konflik horizontal di tengah masyarakat. Berbagai pihak kemudian menyuarakan gagasan ini lebih keras dan diimplementasikan lebih dini dalam kurikulum pendidikan.

Akar pendidikan multikultural, berasal dari perhatian seorang pakar pendidikan Amerika Serikat Prudence Crandall (18-3-1890) yang secara intensif menyebarkan pandangan tentang arti penting latar belakang peserta didik, baik ditinjau dari aspek budaya, etnis, dan agamanya. Pendidikan yang memperhatikan secara sungguh-sungguh latar belakang peserta didik merupakan cikal bakal bagi munculnya pendidikan multikultural. Konsep pendidikan multikultural dalam perjalanannya menyebar luas ke kawasan di luar AS khususnya di negara-negara yang memiliki keragaman etnis, rasionalisme, agama dan budaya seperti di Indonesia. Sedangkan wacana tentang pendidikan multikultural, secara sederhana dapat didefenisikan sebagai "pendidikan untuk/tentang keragaman kebudayaan dalam meresponi perubahan demografis dan kultural lingkungan masyaraka tertentu atau bahkan dunia secara keseluruhan". 8

Selanjutnya James Bank, salah seorang pioner dari pendidikan multikultural dan telah membumikan konsep pendidikan multicultural menjadi ide persamaan pendidikanmengatakan bahwa substansi pendidikan multikultural adalah pendidikan untuk kebebasan (as education for freedom) sekaligus sebagai penyebarluasan gerakan inklusif dalam rangka mempererat hubungan antar sesama (as inclusive and cementing movement). Pendidikan multikultural adalah merupakan suatu wacana yang lintas batas, karena terkait dengan masalah-masalah keadilan sosial (social justice), demokarasi dan hak asasi manusia. ${ }^{9}$

${ }^{7}$ Azyumardi Azra, 2007, Identitas dan Krisis Budaya, Membangun Multikulturalisme Indonesia, Jakarta: FE UI, hlm. 85.

${ }^{8}$ Lasijan, Multikulturalisme dalam Pendidikan Islam, (Jurnal TAPIs NO. 10 Vol. 2, Juli - Desember 2014) Hal. 129

9 H.A.R Tilaar, 2003, Kekusaan Dan Pendidikan Suatu Tinjauan Dan Persepektif Studi Kultural. Indonesia Tera, hlm. 167. 
James Banks juga menyatakan bahwa pengertian pendidikan multikultural sebagai pendidikan untuk people of color. Pengertian ini senada dengan pengertian yang dikemukakan oleh Sleeter bahwa pendidikan multikultural adalah sekumpulan proses yang dilakukan oleh sekolah untuk menentang kelompok yang menindas.15 Pengertian-pengertian ini tidak sesuai dengan konteks pendidikan di Indonesia karena Indonesia memiliki konteks budaya yang berbeda dari Amerika Serikat walaupun keduanya memiliki bangsa dengan multi-kebudayaan. ${ }^{10}$

\section{Konsep pendidikan integratif paideia dari Hans-Georg Gadamer}

Istilah integratif berasal dari bahasa Inggris integrate yang dapat diartikan mengintegratifkan, menyatupadukan, menggabungkan, mempersatukan. Berdasarkan pengertian istilah tersebut, maka pendidikan integratif di Indonesia dikenal dengan pendidikan terpadu. Sekalipun ada tiga bentuk keterpaduan yang dapat ditemukan di Indonesia, yaitu keterpaduan antara berbagai jenis keluarbiasaan, keterpaduan antara anak luar biasa dengan anak normal, dan keterpaduan tersamar (sejumlah anak luar biasa yang berada di sekolah-sekolah umum, tetapi tidak memperoleh layanan pendidikan yang layak). ${ }^{11}$ Pendidikan integratif merupakan model lain bagi Anak Berkebutuhan Khusus (ABK), dimana pendidikan penyandang cacat diintegrasikan bersama anak normal disekolah regular. Pendidikan integratif merupakan sistem pendidikan yang memberikan kesempatan bagi ABK untuk mendapatkan pembelajaran dengan ruang lingkup pembelajaran yang sama dengan anak normal.

Gadamer dilahirkan di Marburg, Jerman, sebagai anak seorang kimiawan farmasi yang belakangan juga menjadi rektor universitas di sana. Gadamer melawan desakan ayahnya agar mempelajari ilmu-ilmu alam dan makin lama makin tertarik akan humaniora. Ia bertumbuh dan belajar di Breslau di bawah Hönigswald, namun tak lama kemudian kembali ke Marburg untuk belajar dengan para filsuf Neo-Kantian Paul Natorp, dan Nicolai

${ }^{10}$ Rustam Ibrahim, PENDIDIKAN MULTIKULTURAL: Pengertian, Prinsip, dan Relevansinya dengan Tujuan Pendidikan Islam (Jurnal : Addin Vol. 7 No. 1, 1 Feruari 2007) hal. 135

${ }^{11}$ Sunardi, "Pendekatan Inklusif Implikasi Managerialnya" Jurnal Rehabilitas Remidiasi. (2003), hlm. 110 
Hartmann. Ia mengikuti kuliah pada Rudolf Bultmann, seorang teolog Protestan yang cukup terkenal. Ia mempertahankan disertasinya pada 1922 dan memperoleh gelar doktor filsafat. ${ }^{12}$

Filsafat pendidikan akan lebih jelas dengan munculnya hal-hal baru apabila kita bisa melihat pendidikan dalam rana tiga tempat, kognitif, afektif, dan psikomotorik dari tiga rana pendidikan ini, teori Gadamer andil besar di tiga rana pokok dalam pendidikan, dimana teori Gadamer dalam mengaplikasikan kesadaran sebagai sarana utama dalam memahami hidup dan bahasa sebagai kunci pemahman yang dapat diartikan sebagai tuntunan untuk menghasilkan makna dealiktika yang memberi sebuah bahasa perantara untuk living tradisi dalam pengantar aktifitas hidup.

Gadamer memberi imagineri baru dalam filsafatnya yang terakomodir dalam tingkat teori antara kesadaran dan bahasa memunculkan makna yang terdalam dalam sebuah aplikasi yang aktual demi mendapatkan sebuah pemahaman baru dalam kreatifitas, artinya staknasi ilmu tak akan mungkin ada, yang ada adalah kreatifitas yang muncul membuat ilmu sangat bervariatif. Pendidikan seolah tak akan usang dengan pemikiran yang diawali dengan sebuah

kesadaran, dan adanya aplikasi yang menimbulkan pengalaman dan keinginan untuk selalu menjadi yang terbaik dan terindah untuk kontribusi keilmuan dalam memaknai arti pembaharuan berfikir demi menghasilkan sebuah metode dan kebenaran ilmu.

\section{E. Konsep pendidikan terpadu: kontribusi neurophilosophy dan non- dualistika fisika kuantum.}

Neurophilosophy atau filsafat ilmu saraf adalah studi interdisipliner ilmu saraf dan filsafat yang mengeksplorasi relevansi studi ilmu saraf dengan argumen yang secara tradisional dikategorikan sebagai filsafat pikiran. Filosofi ilmu saraf berupaya untuk memperjelas metode dan hasil ilmu saraf dengan menggunakan ketelitian konseptual dan metode filsafat ilmu .

Konsep pendidikan terpadu berorientasi pada siswa atau student-oriented dan bukan berorientasi pada mata pelajaran atau subject matter-oriented (Buchori, 1995;157). Keterpaduan ini dilihat dari sudut pandang hak setiap anak, juga anak luar biasa untuk

\footnotetext{
${ }^{12}$ https://id.wikipedia.org/wiki/Hans-Georg_Gadamer
} 
memperoleh layanan pendidikan, tidak berbeda dari anak lainnya. Keterpaduan pendidikan menunjukkan pada pendidikan inklusif (inclusiveeducation), yaitu suatu pendidikan yang dilandasi konsep equal education opportunity. Namun memerlukan guru yang mampu dan memiliki keterampilan professional menghadirkan anak luar biasa dengan anak lainnya dalam pembelajaran secara bermakna.

Pendidikan lebih ditekankan sebagai suatu proses learning dari pada teaching. Peserta didik dirangsang memiliki motivasi untuk mempelajari sesuatu yang harus dipelajari dan continues learning. Namun peserta didik tidak akan dipaksa untuk mempelajari sesuatu yang tidak jngin dipelajari. Materi yang dipelajari bersifat integrated. Pada pendidikan yang demikian, karakteristik individu mendapat tempat yang layak.

Tugas utama guru adalah mengembangkan potensi peserta didik secara maksimal lewat penyajian mata pelajaran. Sebab,pada hakikatnya setiap guru dalam menyampaikan suatu mata pelajaran harus menyadari sepenuhnya bahwa seiring menyampaikan materi pelajaran, bertugas pula mengembangkan watak dan sifat yang mendasari mata pelajaran itu sendiri. Agar guru dapat menyesuaikan dan mengarahkan anak didik sesuai dengan perkembangannya, maka guru harus memperbarui dan meningkatkan ilmu pengetahuan yang dipelajari secara terus-menerus.

Pembelajaran terpadu (integrated learning) merujuk pada pendekatan yang berorientasi pada proses pembelajaran yang lebih bersifat project based (berorientasi pada tuqas), bukan pada contentbased(berorientasi pada materi). Hal ini dikarenakan content base curriculum lebih memfokus pada hafalan isi atau detail teknis, sehingga kurang mengacu pada proses berpikir. Di Singapura, kurikulum berdasarkan pembelajaran terpadu dipangkas volumenya sampai kurang lebih $30 \%$.

\section{F. Konsep pendidikan kosmopolitan dari Bernard J. F. Lonergan.}

Kosmopolitanisme secara epistemologi berasal dari bahasa Yunani yaitu Kosmos dan Politês, Kosmos sendiri memiliki arti "alam semesta" atau "dunia" sementara Politês memiliki arti "warga negara". Secara sederhana kosmopolitan dapat diartikan sebagai warga negara dunia. Hal senada juga tertuang dalam catatan kehidupan Diogenes, yang ketika ditanya "Dari mana asalmu?", Dia menjawab "Saya seorang warga negara dunia (kosmopolitês)" (Diogenes, 1925:71). Secara umum kosmopolitanisme dapat diartikan sebagai gagasan untuk membangkitkan kewarganegaraan dunia dan mempromosikan 
identitas yang tidak berdasarkan teritorial (Breckenridge, 2002:2). Perkembangan globalisasi yang begitu cepat membuat kosmopolitanisme tidak lagi dapat dianalisis hanya melalui sebuah definisi general saja. Karena globalisasi membuat hubungan negara menjadi kompleks, maka dalam Cina kosmopolitanisme harus lebih fokus dan salah satu caranya adalah Cina kosmopolitanisme melalui bentuk-bentuknya.

Fr. Bernard JF Lonergan, CC, SJ (17 Desember 1904 - 26 November 1984) adalah seorang Imam Yesuit Kanada. Dia adalah seorang filsuf-teolog dalam tradisi Thomis dan seorang ekonom dari Buckingham, Quebec. Ia mengajar di Loyola College (Montreal) (sekarang Concordia University), Regis College (sekarang federasi di Universitas Toronto), Universitas Kepausan Gregoriana dan Boston College. Dia adalah penulis Insight: A Study of Human Understanding (1957) dan Method in Theology (1972) yang mengukuhkan generalized empirical method (GEM). University of Toronto Press sedang dalam proses menerbitkan karyanya yang direncanakan akan diterbitkan dalam 25 volume dan diedit oleh staf di Lonergan Research Institute di Regis College. ${ }^{13}$

Lonergan masuk ordo Serikat Yesus pada 1922, memperoleh gelar BA dalam bidang Filsafat dari Heythrop College pada tahun 1929, ditahbiskan menjadi Imam Katolik Roma pada tahun 1933, dan memperoleh gelar Doktor Suci Teologi dari Universitas Kepausan Gregoriana pada tahun 1940. Disertasi doktornya disarankan oleh Charles Boyer, SJ, dan kemudian diterbitkan dengan judul Collected Works as Grace and Freedom: Operative Grace in the thought of St. Thomas Aquinas.

Dalam bidang pendidikan Wawasan sudah ada dalam edisi kedua, dan Lonergan membuat tanda nasional dan internasional. Dia berbicara kepada pendidik selama beberapa hari tentang hal-hal yang terkait dengan Dewey dan Karya Piaget di bidang pendidikan, tetapi juga menyajikan pemikirannya sendiri tentang etika, seni, dan sejarah topik lainnya. Ceramah direkam, ditranskrip dan kemudian diterbitkan sebagai Volume 10, Topik dalam Pendidikan, dalam Koleksi Karya Bernard Lonergan pada tahun 1988.

Seperti judulnya, buku itu terdiri dari serangkaian topik yang dibahas oleh Lonergan, dan sementara secara filosofis, ia tidak bermaksud menghadirkan "filsafat pendidikan" di mana dalam tingkat pendidikan yang sistematis, kohesif, dan terbuka.

\footnotetext{
${ }^{13}$ https://id.wikipedia.org/wiki/Bernard_Lonergan
} 
Menurutnya pendidikan membahas tentang hal-hal yang lebih mendalam terkait dengan pengajaran dan pembelajaran dan mencakup berbagai topik dari epistemologi, etika, dan kewarganegaraan untuk pembentukan dan pengembangan pribadi, kepedulian sosial, dan "pemikiran baru" karena ini memunculkan teori dan praktik pendidikan. Baru contoh-contoh pemikiran baru mengeksplorasi berbagai macam "kecerdasan," "pengetahuan," dan "kemampuan manusia."

Pendidikan membantu para pendidik berpikir secara mendalam, kritis, dan secara kreatif tentang isu-isu besar yang berkaitan dengan kehidupan emosional, intelektual, eksistensial dan sosial manusia, dan membantu para pendidik, dan pada akhirnya orang-orang yang dididik, mengaitkan masalah-masalah ini dan hasilnya penegasan terhadap nilai-nilai dan komitmen dasar seseorang. Sementara praktisi dan administrator di bidang pendidikan bergelut dengan masalah nyata di kelas, di seminar, konferensi aula dan kantor, filosofi pendidikan dapat membantu pendidik mengangkat mata dari jalan segera berjalan kaki untuk mempertimbangkan pandangan yang lebih panjang, kebaikan yang lebih besar, cara yang lebih baik, dan yang paling utama konsekuensi. Adalah pendapat saya bahwa Lonergan, dalam konteks filsafat pendidikan, dapat membantu orang melakukan ini. ${ }^{14}$

Dengan Lonergan, pemikiran filosofis dan konstruksi filsafat tergantung pada dasarnya karena kesadaran manusia. Tanpa pemahaman yang jelas dan akurat apa yang terjadi dalam pola dan operasi kesadaran kita sendiri, katanya, kita dibiarkan hanya untuk mengacaukan semampu kita, hidup pada dasarnya di dunia ekstroversi (atau apa Lonergan menyebut "realisme naif"), berjuang dengan ide-ide yang membingungkan atau keliru tentang budaya dan masyarakat, tentang kehidupan manusia dan apa artinya menjadi manusia, dan akhirnya ide tentang "Realitas." Atas dasar realisme naif dan ekspresi umum dalam berbagai bentuk "Pragmatisme," kita dapat bertahan dalam pendidikan, tentu saja, tetapi sangat sulit untuk dibuat kemajuan substantif, sepenuhnya memuaskan dalam memilah-milah masalah yang kompleks dan mendalam itu hadapi kita hari ini. Pada akhirnya, sebagai realis yang naif, kita mungkin sangat mungkin tidak cukup untuk bertemu tantangan mendalam yang

\footnotetext{
${ }^{14}$ Ivan Gaetz, The Thought of Bernard Lonerganfor Educational Philosophy, Journal of Edication :
} Library Director, Colorado College Hal. 6 
dihadapi budaya kita, atau, seperti yang disarankan oleh filsuf, José Ortega y Gasset, tidak mampu untuk "naik ke tingkat zaman kita. ${ }^{15}$

\section{KESIMPULAN}

\section{A. KESIMPULAN}

- Menurut Pedagogy of the oppressed dari Paulo Freire sistem pendidikan yang pernah ada dan masih sampai saat ini adalah pendidikan gaya "bank" dimana pelajar diberi ilmu agar kelak mendatangkan hasil yang berlipat ganda. Jadi anak didik adalah obyek investasi dan sumber deposito potensial. Mereka tidak berbeda dengan komoditi ekonomis lainya yang lazim dikenal. Depositor atau investor adalah guru yang mewakili lembaga kemasyarakatan yang berkuasa, sementara depositonya berupa ilmu pengetahuan yang diajarkan kepada anak didik.

- Maka Teori Kritis meyakini bahwa ilmu pengetahuan tidak pernah menghasilkan "pengetahuan objektif". Hasil sebuah penelitian sejak semula sudah diarahkan pada metode yang dipakai di dalamnya. Penetapan metode penelitian dengan sendirinya selalu berdasarkan suatu penilaian atau kepentingan. Menurut Habermas, sangatlah penting bagi kita untuk memperhatikan kaitan antara hasil penelitian dan kepentingan kita.

- James Banks juga menyatakan bahwa pengertian pendidikan multikultural sebagai pendidikan untuk people of color. Pengertian ini senada dengan pengertian yang dikemukakan oleh Sleeter bahwa pendidikan multikultural adalah sekumpulan proses yang dilakukan oleh sekolah untuk menentang kelompok yang menindas.

- Filsafat pendidikan akan lebih jelas dengan munculnya hal-hal baru apabila kita bisa melihat pendidikan dalam rana tiga tempat, kognitif, afektif, dan psikomotorik dari tiga rana pendidikan ini, teori Gadamer andil besar di tiga rana pokok dalam pendidikan, dimana teori Gadamer dalam mengaplikasikan kesadaran sebagai sarana utama dalam memahami hidup dan bahasa sebagai kunci pemahman yang dapat diartikan sebagai tuntunan untuk menghasilkan makna dealiktika yang memberi sebuah bahasa perantara untuk living tradisi dalam pengantar aktifitas hidup.

15 Ivan Gaetz, The Thought of Bernard Lonerganfor Educational Philosophy, Journal of Edication : Library Director, Colorado College Hal. 7 
- Pembelajaran terpadu (integrated learning) merujuk pada pendekatan yang berorientasi pada proses pembelajaran yang lebih bersifat project based (berorientasi pada tuqas), bukan pada contentbased(berorientasi pada materi).

- Menurutnya pendidikan kosmopolitan dari Bernard J. F. Lonergan. membahas tentang hal-hal yang lebih mendalam terkait dengan pengajaran dan pembelajaran dan mencakup berbagai topik dari epistemologi, etika, dan kewarganegaraan untuk pembentukan dan pengembangan pribadi, kepedulian sosial, dan "pemikiran baru" karena ini memunculkan teori dan praktik pendidikan.

\section{DAFTAR PUSTAKA}

Aziz, A., \& Saihu, S. (2019). Interpretasi Humanistik Kebahasaan: Upaya Kontekstualisasi Kaidah Bahasa Arab. Arabiyatuna: Jurnal Bahasa Arab, 3(2), 299-214

Azyumardi Azra, 2007, Identitas dan Krisis Budaya, Membangun Multikulturalisme Indonesia, Jakarta: FE UI, hlm. 85.

Freire P. Pedagogi Orang Tertindas /Pedagogy of the Oppressed. ( Continuum: London : 2000.)

Freire, Paulo.1999.Politik Pendidikan : Kebudayaan, Kekuasaan, dan Pembebasan. Diterjemahkan oleh : Agung Prihantoro \& Fuad Arif Fudiyanto.Yogyakarta : ReaD \& Pustaka Pelajar

H.A.R Tilaar, 2003, Kekusaan Dan Pendidikan Suatu Tinjauan Dan Persepektif Studi Kultural. Indonesia Tera, hlm. 167.

http://pelitaku.sabda.org/franz_kafka

https://akhmadsudrajat.wordpress.com/2010/07/22/pendidikan-kritis/

https://id.wikipedia.org/wiki/Bernard_Lonergan

https://id.wikipedia.org/wiki/Hans-Georg_Gadamer

https://id.wikipedia.org/wiki/Paulo_Freire

https://www.academia.edu/1845413/MEMBERDAYAKAN_YANG_TERTINDAS_DARI_F RANKFURT_KE_YOGYAKARTA 
Ivan Gaetz, The Thought of Bernard Lonerganfor Educational Philosophy, Journal of Edication : Library Director, Colorado College Hal. 6

Ivan Gaetz, The Thought of Bernard Lonerganfor Educational Philosophy, Journal of Edication : Library Director, Colorado College Hal. 7

Lasijan, Multikulturalisme dalam Pendidikan Islam, (Jurnal TAPIs NO. 10 Vol. 2, Juli Desember 2014) Hal. 129

Mubin, F. (2019). TAFSIR EMANSIPATORIS: PEMBUMIAN METODOLOGI TAFSIR PEMBEBASAN. Mumtaz: Jurnal Studi Al-Quran dan Keislaman, 3(1), 131-151.

Mubin, F. KEADILAN DALAM GENDER: KAJIAN KEPEMIMPINAN WANITA DALAM ISLAM1,

Mubin, F. MODEL-MODEL PEMBELAJARAN BERBASIS MADRASAH DAN KEGIATAN LAIN YANG DIPERLUKAN DI DALAMNYA (FAKTOR PENDUKUNGNYA).

Ronaldo, R., Zulfikar, A., Saihu, Ismail, \& Wekke, I. S. (2020). International relations of the asia pacific in the age of trump. Journal of Environmental Treatment Techniques, 8(1), 244-246.

Rustam Ibrahim, PENDIDIKAN MULTIKULTURAL: Pengertian, Prinsip, dan Relevansinya dengan Tujuan Pendidikan Islam (Jurnal : Addin Vol. 7 No. 1, 1 Feruari 2007) hal. 135

Şahin, C. RELIGIA.

Saihu, Aziz, A., Mubin, F., \& Sarnoto, A. Z. (2020). Design of islamic education based on local wisdom (An analysis of social learning theories in forming character through ngejot tradition in bali). International Journal of Advanced Science and Technology, 29(6), 1278-1293.

Saihu, M. (2019). Urgensi 'Urf dalam Tradisi Male dan Relevansinya dalam Dakwah Islam di Jembrana-Bali. Jurnal Bimas Islam, 12(1), 173-201.

Saihu, M. (2019). Merawat Pluralisme Merawat Indonesia (Potret Pendidikan Pluralisme Agama Di Jembrana-Bali). Deepublish.

Saihu, M. M., \& Aziz, A. (2020). Implementasi Metode Pendidikan Pluralisme Dalam Mata Pelajaran Pendidikan Agama Islam. Belajea; Jurnal Pendidikan Islam, 5(1), 131-150.

Saihu, S. (2019). IMPLEMENTASI MANAJEMEN BALANCED SCORECARD DI PONDOK PESANTREN JAM'IYYAH ISLAMIYYAH TANGERANG SELATAN. Mumtaz: Jurnal Studi Al-Quran dan Keislaman, 3(1), 1-22.

Saihu, S. (2019). KOMUNIKASI PENDIDIK TERHADAP ANAK BERKEBUTUHAN KHUSUS DI SEKOLAH KHUSUS ASY-SYIFA LARANGAN. Andragogi: Jurnal Pendidikan Islam dan Manajemen Pendidikan Islam, 1(3), 418-440.

Saihu, S. (2019). KONSEP MANUSIA DAN IMPLEMENTASINYA DALAM PERUMUSAN TUJUAN PENDIDIKAN ISLAM MENURUT MURTADHA MUTHAHHARI. Andragogi: Jurnal Pendidikan Islam dan Manajemen Pendidikan Islam, 1(2), 197-217.

Saihu, S. (2019). PENDIDIKAN KARAKTER BERBASIS KEARIFAN LOKAL (STUDI DI JEMBRANA BALI). Edukasi Islami: Jurnal Pendidikan Islam, 8(01), 69-90. 
Saihu, S. (2019). Pendidikan Pluralisme Agama: Kajian tentang Integrasi Budaya dan Agama dalam Menyelesaikan Konflik Sosial Kontemporer. Jurnal Indo-Islamika, 9(1), $67-90$,

Saihu, S. (2019). RINTISAN PERADABAN PROFETIK UMAT MANUSIA MELALUI PERISTIWA TURUNNYA ADAM AS KE-DUNIA. Mumtaz: Jurnal Studi Al-Quran dan Keislaman, 3(2), 268-279,

Saihu, S. (2020). ETIKA MENUNTUT ILMU MENURUT KITAB TA'LIM MUTA'ALIM. Al Amin: Jurnal Kajian Ilmu dan Budaya Islam, 3(1), 99-112.

Saihu, S. (2020). KONSEP PEMBAHARUAN PENDIDIKAN ISLAM MENURUT FAZLURRAHMAN. Andragogi: Jurnal Pendidikan Islam dan Manajemen Pendidikan Islam, 2(1), 82-95.

Saihu, S. (2020). Pendidikan sosial yang terkandung dalam Surat At-Taubah Ayat 7172. Edukasi Islami: Jurnal Pendidikan Islam, 9(01), 127-148.

Saihu, S. (2020). The Effect of Using Talking Stick Learning Model on Student Learning Outcomes in Islamic Primary School of Jamiatul Khair, Ciledug Tangerang. Tarbawi: Jurnal Keilmuan Manajemen Pendidikan, 6(01), 61-68.

Saihu, S., \& Mailana, A. (2019). Teori pendidikan behavioristik pembentukan karakter masyarakat muslim dalam tradisi Ngejot di Bali. Ta'dibuna: Jurnal Pendidikan Islam, 8(2), 163-176.

Saihu, S., \& Marsiti, M. (2019). PENDIDIKAN KARAKTER DALAM UPAYA MENANGKAL RADIKALISME DI SMA NEGERI 3 KOTA DEPOK, JAWA BARAT. Andragogi: Jurnal Pendidikan Islam dan Manajemen Pendidikan Islam, 1(1), 23-54.

Saihu, S., \& Rohman, B. (2019). PEMBENTUKAN KARAKTER MELALUI MODEL PENDIDIKAN TRANSFROMATIFE LEARNING PADA SANTRI DI PONDOK PESANTREN NURUL IKHLAS BALI. Edukasi Islami: Jurnal Pendidikan Islam, 8(02), 435-452.

Saihu, S., \& Taufik, T. (2019). PERLINDUNGAN HUKUM BAGI GURU. Al Amin: Jurnal Kajian Ilmu dan Budaya Islam, 2(2), 105-116.

Sunardi, "Pendekatan Inklusif Implikasi Managerialnya" Jurnal Rehabilitas Remidiasi. (2003), hlm. 110 